\title{
Testing the anniversary reaction: causal effects of bereavement in a nationwide follow-up study from Sweden
}

\section{Citation}

Rostila, Mikael, Jan Saarela, Ichiro Kawachi, and Anders Hjern. 2015. “Testing the Anniversary Reaction: Causal Effects of Bereavement in a Nationwide Follow-up Study from Sweden."

European Journal of Epidemiology 30 (3): 239-47. https://doi.org/10.1007/s10654-015-9989-5.

\section{Permanent link}

http://nrs.harvard.edu/urn-3:HUL.InstRepos:41275576

\section{Terms of Use}

This article was downloaded from Harvard University's DASH repository, WARNING: This file should NOT have been available for downloading from Harvard University's DASH repository.

\section{Share Your Story}

The Harvard community has made this article openly available.

Please share how this access benefits you. Submit a story.

\section{Accessibility}




\title{
Testing the anniversary reaction: causal effects of bereavement in a nationwide follow-up study from Sweden
}

\author{
Mikael Rostila $\cdot$ Jan Saarela $\cdot$ Ichiro Kawachi $\cdot$ \\ Anders Hjern
}

Received: 20 August 2014/ Accepted: 5 January 2015/Published online: 17 January 2015

(C) Springer Science+Business Media Dordrecht 2015

\begin{abstract}
Lingering grief associated with the death of a loved one has been hypothesized to precipitate acute health events among survivors on anniversary dates. We sought to study excess mortality risk in parents around the death date and birth date of a deceased child as an indication of a "bereavement effect". We conducted a population based follow-up study using Swedish registries including links between children and parents. All biological and Swedishborn parents who experienced the death of a minor child born were observed during the period 1973-2008 $(n=48,666)$. An increased mortality risk was found during the week of a child's death among mothers who lost a child aged $0-17$ years $\quad($ SMRR $=1.46,95 \%$ CI $0.98-2.17)$. The association was stronger among mothers who lost a child aged $1-17$ years $($ SMRR $=1.89,95 \%$ CI 0.97-3.67) as compared to those who lost an infant (SMRR $=1.29,95 \%$
\end{abstract}

M. Rostila ( $\square)$

Department of Sociology and Centre for Health Equity Studies, Stockholm University, 10691 Stockholm, Sweden

e-mail: mikael.rostila@chess.su.se

J. Saarela

University of Helsinki and Åbo Akademi University,

PO Box 311, 65101 Vaasa, Finland

e-mail: jan.saarela@abo.fi

I. Kawachi

Harvard School of Public Health, 677 Huntington Avenue,

Boston, MA 02115-6096, USA

e-mail: ikawachi@hsph.harvard.edu

\section{A. Hjern}

Clinical Epidemiology, Department of Medicine, Karolinska Institutet and Centre for Health Equity Studies (CHESS),

Stockholm University/Karolinska Institutet, Sveavägen 160,

10691 Stockholm, Sweden

e-mail: anders.hjern@chess.su.se
CI 0.78-2.12). Cardiovascular diseases and suicides were overrepresented as causes of death in mothers who died around the anniversary. We found no significant increase in the mortality risk around the date of child's birth, nor any suggestion of excess mortality risk among fathers, but rather a depression of paternal death $(\mathrm{SMRR}=0.60,95 \%$ CI 0.34-1.03). Our study indicates an anniversary reaction among mothers who lost a young child. These results suggest that bereavement per se could have an effect on health and mortality which should be acknowledged by public health professionals working with bereaved people.

Keywords Bereavement $\cdot$ Grief $\cdot$ Anniversary $\cdot$ Sweden . Mortality

\section{Introduction}

In economically advanced societies, normally the death of parents precedes the death of children in the life cycle. The death of a child before their parents is therefore considered one of the most stressful and traumatic life events a person may encounter, especially when it involves a young child [1]. Some studies suggest that parents suffer more intense grief after the death of a child compared to the bereavement following the death of either a spouse or a parent [2-4].

In general, bereavement is thought to adversely affect health through both acute psycho-physiological mechanisms, which has been observed to follow episodes of intense psychogenic shock $[1,5,6]$, as well as through longer-term mechanisms involving changes in health-related behaviours such as smoking, increased alcohol consumption, poor diet and exercise habits [1, 7, 8]. Obviously, grief also adversely influences emotional states 
which can result in psychological and psychosomatic health problems and suicide [9].

Most empirical research linking the death of a child to the health of parents suggests adverse health effects. Studies have found that the death of a young child increases parental mortality from all causes [1], as well as the risk of depressive symptoms [10], certain types of cancer [11], myocardial infarction [12], poor self-rated health [13], diabetes [14], and suicide [15]. Yet, some analyses have found no increase in risk in parents with regard to general health status [16], cancer morbidity [17], or stroke [18]. Studies have also examined the duration of bereavement. Some research that has examined longerterm consequences following child deaths has found that grief persists for the remainder of the parent's life [19-21], while others show evidence for shorter-term consequences [22-24].

Yet we do not know from previous studies whether the increased parental mortality risk subsequent to a child's death reflects a true bereavement effect or if it caused by confounding. An important threat to causal inference in this area of research is the possibility that the death or ill health of children and parents share a common prior cause, i.e., that there is confounding of the relationship by an unobserved third variable $[28,29]$. For example, if a child dies of a chronic disease with a strong genetic component (e.g. lung failure caused by cystic fibrosis) and the parent dies shortly later, this may be a marker of genetic or biological similarity. Another possibility is that the death of the child and the parent originates from factors related to environmental conditions shared by parents and their children (e.g. material circumstances, life styles etc.).

One way to overcome these problems is to analyse mortality around anniversaries and other significant dates, such as birthdays. Being unrelated to biological and social factors, they can be considered reflecting bereavement reactions to the child's death per se. In the psychoanalytic literature, the anniversary reaction refers to a phenomenon where temporal triggers precipitate acute reactions including grief, anger, depression and despair associated with the traumatic event on the date of the child's death or birth [30]. This reaction may give rise to somatic symptoms, depression, psychosis, suicide or even homicide [31]. Previous studies have found a higher risk of psychiatric and physical disorders around the anniversary of the death of a child [32]. More suicides than expected have also been found to occur before and after the anniversary of a family member's death $[33,34]$.

The idea behind anniversaries to capture a bereavement effect lies in the notion that, among people who had experienced the death of a loved one, the occurrence of their own death on one specific calendar day of the year can be considered exogenous with respect social, biological and other potential confounders. The intuition is consequently that child and subsequent parental deaths at the same day of different calendar years must be considered random with respect to other potential factors that may influence collateral health and hence related to the remembrance of a traumatic event experienced on that particular calendar day.

It is nevertheless possible that mothers and fathers differ in this respect. Mothers tend to be the primary attachment figure for young children [25, 26]. The mother-child relationship is characterized by more shared values and attitudes, greater affective closeness and greater stability than the father-child relationship [26]. Research also has indicated that mothers are more important than fathers for the provision of emotional and material support across the life course [27]. Child's death might involve greater distress and grief for mothers and thereby more detrimental health consequences, which has been confirmed by earlier studies $[1,28]$. If an anniversary reaction can be documented, it is therefore most likely observable for mothers.

By observing parental mortality around the death date and birth date of children one can consequently examine whether there is an excess risk of death in mothers and fathers who have lost a child around these critical dates. This quasi-experimental approach can be considered a test for whether there is a true bereavement effect in terms of a causal effect of the death of a child on parental mortality. Hence, our aim was to undertake the first study of parental mortality following the death of a minor child around the anniversary since the loss and birth of a deceased child, using intergenerational linked data from nationwide Swedish registers.

\section{Methods}

The data came from multiple-linked Swedish registries and consist of all children born in Sweden 1973-2008, with linkage to the parents. The study was approved by the Regional Ethical Review board of Stockholm (No. 2014/415-31/5). We studied biological parents born in Sweden who experienced the death of a minor child during the period 1973-2008. Parents who died within 28 days after the child's death were excluded to ensure that mortality of members of the same family was not related to the same cause, such as an accident. This total population of bereaved parents consisted of 26,087 mothers and 22,579 fathers.

Our focus was on observing whether there is excess mortality around the anniversary of a child's death and around the anniversary of a deceased child's birth. We estimated mortality rate ratios, which is the ratio of the parental mortality rate during a period of a specific length, 
such as a day or a week, and the mortality rate outside the period.

The anniversary reaction is by definition considered to be unrelated to parental, child and environmental characteristics, or other confounders. The exogeneity implies that adding control variables to the models should have no major influence on the estimates for the parental mortality rate around the anniversary of a child's death or birth. We standardised for a number of control variables that generally influence the death risk; parent's age, observation year, time since child's death, mother's age at delivery, child's sex, child's birth order, number of siblings, multiplicity, and main cause of child's death. They are further described in the footnotes of Table 4 in the next section. As expected, these standardised mortality rate ratios, which are the ones reported, estimated marginally from the unstandardised ones, which is at the third or lower decimal level. Initially we also included dummies for deaths around Christmas and Midsummer, because death rates may increase during holidays. These variables did not provide statistical improvement and were excluded from the final models presented here.

We began by studying mothers and fathers together, but realised that separate analyses had to be undertaken, because an elevation in the mortality risk around the anniversary could be documented only for mothers. We stratified according to child's age at death, and experimented with alternative time windows of exposure around the anniversary. The results reported here use categorisations and models that best fit the data, and which summarise the overall findings.

\section{Results}

Parents who had lost a child were found to have an elevated mortality risk at the anniversary of the child's death. The mortality rate was 1.26 that as would be expected if deaths were equally distributed over the calendar year (upper panel of Table 1). A closer inspection of the data revealed, however, that there was an anniversary effect only for mothers and primarily related to the anniversary of death. On the death date of a minor child, bereaved mothers had twice (2.03) the mortality rate as would be expected if deaths were equally distributed over the calendar year (middle panel of Table 1). Fathers, on the other hand, had a depressed death risk around the anniversary of a deceased child's death or birth (lower panel of Table 1).

Also 1-3 days before and after the anniversary, there was an elevation in the maternal mortality rate. On the anniversary birth date of the deceased child there was some excess maternal mortality as well, albeit somewhat more muted-mortality rate ratio of 1.62 . Stratifying by child's age at death, we can see that the effect of an infant's (children less than 1 year old) death date was concentrated to the anniversary, while the effect of a non-infant's death date was somewhat more dispersed around this date. Excess mortality around the birth date of a deceased child was noticeable foremost with respect to the anniversary of non-infant children.

The excess mortality in mothers around the death date of a child was primarily associated with child deaths from external causes if the child died at non-infant age, and with child deaths from sudden infant death syndrome if the child died during infancy (Table 2). Cardiovascular diseases and suicides were overrepresented as causes of death in mothers who died around the anniversary (Table 3).

To increase the statistical power while standardising for effects of the control variables, we also examined whether there was excess parental mortality in the anniversary week (the same date and 3 days before and after this date) and each of the 4 weeks preceding and following the anniversary week. Again, fathers tended to have a depressed mortality risk around or at the anniversary, whereas the anniversary effect in mothers was found primarily during the anniversary week of the death of the child, and was lower before and after this week (Table 4). For mothers, the standardised mortality rate ratio in the anniversary week and that in the period outside the 9-week period considered here was 1.42 and close to statistically significant at the five per cent level (95\% CI 0.96-2.12). This effect was particularly strong for those who experienced the death of a non-infant child, or 1.82 (95\% CI 0.93-3.54), while it was weaker for those who experienced the death of an infant child, or 1.27 (95\% CI 0.77-2.09). The birth week was only weakly associated with an anniversary effect, and that was if the child died at an age beyond infancy; the mortality rate ratio was 1.25 (95\% CI 0.56-2.82). Yet there were some indications that both maternal and paternal mortality was elevated some week after the anniversary, but the confidence intervals were too wide to reach any firm conclusions.

An anniversary reaction was consequently found concentrated to the week of a child's death, and observed only among mothers. The overall standardised mortality rate of mothers, irrespective of child's age at death, during the anniversary week of a child's death was 1.46 (95\% CI 0.98-2.17) (Table 5). For children who died at infant age and beyond infancy, the standardised ratios were 1.29 (95\% CI 0.78-2.12) and 1.89 (95\% CI 0.97-3.67), respectively. The birth week of a deceased child did not seem associated with an anniversary effect in mothers, since the standardised mortality rate ratio was close to unity. We did not find evidence supporting an anniversary effect among fathers, but rather an attenuation of the mortality risk. The overall standardised mortality rate of 
Table 1 Mortality rate ratios (MR) and number of deaths $(\mathrm{N})$ of mothers and fathers around the anniversaries of death and birth of a deceased minor child, by child's age at death
The data consist of all biological parents to children born 1973-2008 who had experienced the death of a minor child in 1973-2008

Parents who died within 28 days after the child has died are excluded

Mortality rate ratio is the ratio of the number of observed parental deaths during the specific period referred to and the expected number of parental deaths if deaths were equally distributed over the calendar year

\begin{tabular}{|c|c|c|c|c|c|c|c|c|c|c|c|c|}
\hline & \multicolumn{6}{|c|}{ According to death date of child } & \multicolumn{6}{|c|}{ According to birth date of child } \\
\hline & \multicolumn{2}{|c|}{$0-17$ years } & \multicolumn{2}{|c|}{ Infants } & \multicolumn{2}{|c|}{$1-17$ years } & \multicolumn{2}{|c|}{$0-17$ years } & \multicolumn{2}{|c|}{ Infants } & \multicolumn{2}{|c|}{$1-17$ years } \\
\hline & MR & $\mathrm{N}$ & MR & $\mathrm{N}$ & MR & $\mathrm{N}$ & MR & $\mathrm{N}$ & MR & $\mathrm{N}$ & MR & $\mathrm{N}$ \\
\hline \multicolumn{13}{|l|}{ Mothers + fathers } \\
\hline 15-28 days before & 1.03 & 80 & 1.04 & 56 & 1.01 & 24 & 0.98 & 76 & 1.00 & 54 & 0.93 & 22 \\
\hline 8-14 days before & 1.05 & 41 & 1.26 & 34 & 0.59 & 7 & 1.29 & 50 & 1.33 & 36 & 1.18 & 14 \\
\hline 4-7 days before & 0.72 & 16 & 0.78 & 12 & 0.59 & 4 & 1.08 & 24 & 1.16 & 18 & 0.89 & 6 \\
\hline 1-3 days before & 0.96 & 16 & 0.86 & 10 & 1.18 & 6 & 0.84 & 14 & 0.78 & 9 & 0.99 & 5 \\
\hline Anniversary & 1.26 & 7 & 1.29 & 5 & 1.18 & 2 & 0.72 & 4 & 0.52 & 2 & 1.18 & 2 \\
\hline $1-3$ days after & 0.90 & 15 & 0.78 & 9 & 1.18 & 6 & 0.96 & 16 & 1.12 & 13 & 0.59 & 3 \\
\hline 4-7 days after & 0.86 & 19 & 0.84 & 13 & 0.89 & 6 & 1.04 & 23 & 1.23 & 19 & 0.59 & 4 \\
\hline 8-14 days after & 0.95 & 37 & 1.00 & 27 & 0.85 & 10 & 0.87 & 34 & 0.81 & 22 & 1.01 & 12 \\
\hline 15-28 days after & 0.91 & 71 & 0.91 & 49 & 0.93 & 22 & 0.84 & 65 & 0.87 & 47 & 0.76 & 18 \\
\hline \multicolumn{13}{|l|}{ Mothers } \\
\hline 15-28 days before & 1.04 & 36 & 1.12 & 28 & 0.83 & 8 & 1.19 & 41 & 1.16 & 29 & 1.24 & 12 \\
\hline 8-14 days before & 0.87 & 15 & 1.04 & 13 & 0.41 & 2 & 1.22 & 21 & 1.21 & 15 & 1.24 & 6 \\
\hline 4-7 days before & 0.71 & 7 & 0.70 & 5 & 0.72 & 2 & 0.71 & 7 & 0.84 & 6 & 0.36 & 1 \\
\hline 1-3 days before & 1.49 & 11 & 1.31 & 7 & 1.93 & 4 & 0.95 & 7 & 0.75 & 4 & 1.45 & 3 \\
\hline Anniversary & 2.03 & 5 & 2.25 & 4 & 1.45 & 1 & 1.62 & 4 & 1.12 & 2 & 2.90 & 2 \\
\hline 1-3 days after & 1.22 & 9 & 0.94 & 5 & 1.93 & 4 & 0.95 & 7 & 1.12 & 6 & 0.48 & 1 \\
\hline 4-7 days after & 1.11 & 11 & 0.98 & 7 & 1.45 & 4 & 0.91 & 9 & 0.98 & 7 & 0.72 & 2 \\
\hline 8-14 days after & 0.93 & 16 & 1.04 & 13 & 0.62 & 3 & 1.04 & 18 & 0.80 & 10 & 1.66 & 8 \\
\hline 15-28 days after & 0.84 & 29 & 0.88 & 22 & 0.72 & 7 & 0.87 & 30 & 1.00 & 25 & 0.52 & 5 \\
\hline \multicolumn{13}{|l|}{ Total number of } \\
\hline Child deaths & \multicolumn{2}{|c|}{26,087} & \multicolumn{2}{|c|}{18,891} & \multicolumn{2}{|c|}{7,196} & \multicolumn{2}{|c|}{26,087} & \multicolumn{2}{|c|}{18,891} & \multicolumn{2}{|c|}{7,196} \\
\hline Maternal deaths & \multicolumn{2}{|c|}{901} & \multicolumn{2}{|c|}{649} & \multicolumn{2}{|c|}{252} & \multicolumn{2}{|c|}{901} & \multicolumn{2}{|c|}{649} & \multicolumn{2}{|c|}{252} \\
\hline Fathers & & & & & & & & & & & & \\
\hline 15-28 days before & 1.02 & 44 & 0.96 & 28 & 1.14 & 16 & 0.81 & 35 & 0.86 & 25 & 0.71 & 10 \\
\hline 8-14 days before & 1.20 & 26 & 1.44 & 21 & 0.71 & 5 & 1.34 & 29 & 1.44 & 21 & 1.14 & 8 \\
\hline 4-7 days before & 0.73 & 9 & 0.84 & 7 & 0.50 & 2 & 1.38 & 17 & 1.44 & 12 & 1.25 & 5 \\
\hline $1-3$ days before & 0.54 & 5 & 0.48 & 3 & 0.67 & 2 & 0.76 & 7 & 0.80 & 5 & 0.67 & 2 \\
\hline Anniversary & 0.65 & 2 & 0.48 & 1 & 1.00 & 1 & 0.00 & 0 & 0.00 & 0 & 0.00 & 0 \\
\hline 1-3 days after & 0.65 & 6 & 0.64 & 4 & 0.67 & 2 & 0.97 & 9 & 1.12 & 7 & 0.67 & 2 \\
\hline 4-7 days after & 0.65 & 8 & 0.72 & 6 & 0.50 & 2 & 1.13 & 14 & 1.44 & 12 & 0.50 & 2 \\
\hline 8-14 days after & 0.97 & 21 & 0.96 & 14 & 1.00 & 7 & 0.74 & 16 & 0.82 & 12 & 0.57 & 4 \\
\hline 15-28 days after & 0.97 & 42 & 0.93 & 27 & 1.07 & 15 & 0.81 & 35 & 0.75 & 22 & 0.93 & 13 \\
\hline Total number of & & & & & & & & & & & & \\
\hline Child deaths & 22 , & & 15,5 & & & & 22 , & & 15,5 & & & \\
\hline Paternal deaths & & & & 61 & & & & & & 61 & & \\
\hline
\end{tabular}

increased mortality risk in parents around the death day and birth day of a deceased child. We found indications of an increased mortality risk during the week of a child's death among mothers who lost a young child. The association was stronger among mothers who lost a child aged 1-17 years as compared to those who lost an infant. We found no increase in the mortality risk around the date of child's birth, nor among fathers.

To the extent that the anniversary after the death of a child triggers feelings of grief and represents a reminder of 
Table 2 Mortality rate ratios (MR) and number of deaths $(\mathrm{N})$ of mothers at the death week and birth week of a deceased minor child, by child's age at death and child's main cause of death

Week refers to the anniversary $\mp 3$ days

Mortality rate ratio is the ratio of the number of observed parental deaths during the week and the expected number of parental deaths if deaths were equally distributed over the calendar year

\begin{tabular}{|c|c|c|c|c|c|c|}
\hline & \multicolumn{2}{|c|}{$0-17$ years } & \multicolumn{2}{|c|}{ Infants } & \multicolumn{2}{|c|}{$1-17$ years } \\
\hline & MR & $\mathrm{N}$ & MR & $\mathrm{N}$ & MR & $\mathrm{N}$ \\
\hline \multicolumn{7}{|l|}{ According to death date of child } \\
\hline Congenital malformations & 1.37 & 5 & 1.36 & 4 & 1.41 & 1 \\
\hline Sudden infant death syndrome & 1.53 & 2 & 1.58 & 2 & 0.00 & 0 \\
\hline External causes & 2.61 & 5 & 0.00 & 0 & 2.90 & 5 \\
\hline All other causes & 1.25 & 13 & 1.24 & 10 & 1.27 & 3 \\
\hline All causes & 1.45 & 25 & 1.29 & 16 & 1.86 & 9 \\
\hline \multicolumn{7}{|l|}{ According to birth date of child } \\
\hline Congenital malformations & 0.55 & 2 & 0.34 & 1 & 1.41 & 1 \\
\hline Sudden infant death syndrome & 1.53 & 2 & 1.58 & 2 & 0.00 & 0 \\
\hline External causes & 0.52 & 1 & 0.00 & 0 & 0.58 & 1 \\
\hline All other causes & 1.25 & 13 & 1.12 & 9 & 1.70 & 4 \\
\hline All causes & 1.04 & 18 & 0.96 & 12 & 1.24 & 6 \\
\hline \multicolumn{7}{|l|}{ Number of child deaths } \\
\hline Congenital malformations & \multicolumn{2}{|c|}{5,263} & \multicolumn{2}{|c|}{4,561} & \multicolumn{2}{|c|}{702} \\
\hline Sudden infant death syndrome & \multicolumn{2}{|c|}{2,000} & \multicolumn{2}{|c|}{1,965} & \multicolumn{2}{|c|}{35} \\
\hline External causes & \multicolumn{2}{|c|}{2,539} & \multicolumn{2}{|c|}{218} & \multicolumn{2}{|c|}{2,321} \\
\hline All other causes & \multicolumn{2}{|c|}{16,285} & \multicolumn{2}{|c|}{12,147} & \multicolumn{2}{|c|}{4,138} \\
\hline All causes & \multicolumn{2}{|c|}{26,087} & \multicolumn{2}{|c|}{18,891} & \multicolumn{2}{|c|}{7,196} \\
\hline Total number of maternal deaths & \multicolumn{2}{|c|}{901} & \multicolumn{2}{|c|}{649} & \multicolumn{2}{|c|}{252} \\
\hline
\end{tabular}

Table 3 Distribution (\%) of deaths by main cause in mothers who died the same week as the deceased minor child died or was born, and in all bereaved mothers, by child's age at death

\begin{tabular}{|c|c|c|c|}
\hline & $0-17$ years & Infants & $1-17$ years \\
\hline \multicolumn{4}{|c|}{ Died same week as child died } \\
\hline Cardiovascular diseases & 20.0 & 31.3 & 0.0 \\
\hline Suicide & 16.0 & 12.5 & 22.2 \\
\hline Other external causes & 0.0 & 0.0 & 0.0 \\
\hline All other causes & 64.0 & 56.3 & 77.8 \\
\hline Total number of deaths & 25 & 16 & 9 \\
\hline \multicolumn{4}{|c|}{ Died same week as child was born } \\
\hline Cardiovascular diseases & 11.1 & 16.7 & 0.0 \\
\hline Suicide & 27.8 & 33.3 & 16.7 \\
\hline Other external causes & 0.0 & 0.0 & 0.0 \\
\hline All other causes & 61.1 & 50.0 & 83.3 \\
\hline Total number of deaths & 18 & 12 & 6 \\
\hline \multicolumn{4}{|l|}{ All bereaved mothers } \\
\hline Cardiovascular diseases & 14.7 & 14.3 & 15.5 \\
\hline Suicide & 6.2 & 6.0 & 6.7 \\
\hline Other external causes & 9.8 & 10.3 & 8.3 \\
\hline All other causes & 69.4 & 69.3 & 69.4 \\
\hline Total number of deaths & 901 & 649 & 252 \\
\hline
\end{tabular}

Week refers to the anniversary $\mp 3$ days

this tragic event it could contribute to several negative outcomes. Higher mortality among mothers around the anniversary since the death of a child could reflect a bereavement reaction to the child's death per se. It might be that the anniversary triggers feelings such as grief, anger, depression and despair associated with the traumatic event [30,31], and contribute to increased levels of acute stress or severe mental disorders. It seems less likely that longer-term mechanisms contribute to an increased mortality in bereaved parents on one specific calendar day of the year, but such deaths should rather be scattered throughout the year. Thus, our findings among mothers indicate that associations between child deaths and subsequent mortality among parents could be causal and reflect consequences of bereavement.

The findings indicate also that the gender of the parent is crucial for health consequences following child loss. We found associations only among mothers around the anniversary since the death of a child, which suggest greater distress and grief for mothers and thereby more detrimental health consequences as compared to fathers. The higher mortality in mothers around the anniversary may be explained by the fact that mothers generally are the primary attachment figure for young children [25, 26]. Yet, differences in attachment by sex cannot explain the lower mortality in fathers around anniversaries. Explanations for this finding should therefore be further studied. Furthermore, the higher mortality among mothers who experienced the loss of an older child (1-17 years) may reflect higher relationship quality between mothers and their children and thereby more severe consequences [26, 27]. 
Table 4 Standardised mortality rate ratios of mothers and fathers around the death week and birth week of a deceased minor child, by child's age at death

\begin{tabular}{|c|c|c|c|}
\hline & $0-17$ years & Infants & $1-17$ years \\
\hline \multicolumn{4}{|c|}{ Mothers, around child's death } \\
\hline 4 weeks before & $0.80(0.47-1.35)$ & $0.79(0.42-1.48)$ & $0.81(0.30-2.17)$ \\
\hline 3 weeks before & $0.85(0.51-1.42)$ & $0.95(0.54-1.69)$ & $0.61(0.19-1.89)$ \\
\hline 2 weeks before & $0.63(0.35-1.14)$ & $0.71(0.37-1.38)$ & $0.40(0.10-1.62)$ \\
\hline 1 week before & $1.08(0.69-1.71)$ & $1.11(0.65-1.89)$ & $1.01(0.42-2.45)$ \\
\hline Same week & $1.42(0.96-2.12)$ & $1.27(0.77-2.09)$ & $1.82(0.93-3.54)$ \\
\hline 1 week after & $0.80(0.47-1.35)$ & $0.87(0.48-1.59)$ & $0.61(0.19-1.89)$ \\
\hline 2 weeks after & $0.68(0.39-1.21)$ & $0.87(0.48-1.59)$ & $0.20(0.03-1.44)$ \\
\hline 3 weeks after & $1.20(0.78-1.85)$ & $1.35(0.83-2.19)$ & $0.81(0.30-2.17)$ \\
\hline 4 weeks after & $0.85(0.51-1.42)$ & $0.56(0.26-1.17)$ & $1.61(0.80-3.27)$ \\
\hline \multicolumn{4}{|c|}{ Mothers, around child's birth } \\
\hline 4 weeks before & $0.92(0.56-1.51)$ & $1.04(0.60-1.79)$ & $0.63(0.20-1.96)$ \\
\hline 3 weeks before & $0.69(0.39-1.22)$ & $0.80(0.43-1.49)$ & $0.42(0.10-1.68)$ \\
\hline 2 weeks before & $0.81(0.48-1.37)$ & $0.72(0.37-1.38)$ & $1.04(0.43-2.53)$ \\
\hline 1 week before & $1.10(0.69-1.73)$ & $0.96(0.54-1.69)$ & $1.46(0.69-3.10)$ \\
\hline Same week & $1.04(0.65-1.66)$ & $0.96(0.54-1.69)$ & $1.25(0.56-2.82)$ \\
\hline 1 week after & $1.04(0.65-1.66)$ & $1.11(0.66-1.90)$ & $0.83(0.31-2.25)$ \\
\hline 2 weeks after & $0.69(0.39-1.22)$ & $0.64(0.32-1.28)$ & $0.83(0.31-2.25)$ \\
\hline 3 weeks after & $1.79(1.25-2.56)$ & $1.75(1.14-2.68)$ & $1.88(0.96-3.66)$ \\
\hline 4 weeks after & $0.86(0.52-1.44)$ & $0.72(0.37-1.38)$ & $1.25(0.56-2.82)$ \\
\hline \multicolumn{4}{|c|}{ Fathers, around child's death } \\
\hline 4 weeks before & $1.22(0.83-1.78)$ & $1.26(0.80-2.00)$ & $1.12(0.55-2.25)$ \\
\hline 3 weeks before & $0.77(0.47-1.24)$ & $0.60(0.31-1.16)$ & $1.12(0.55-2.25)$ \\
\hline 2 weeks before & $0.81(0.51-1.29)$ & $0.73(0.40-1.33)$ & $0.98(0.46-2.07)$ \\
\hline 1 week before & $0.81(0.51-1.29)$ & $0.87(0.50-1.50)$ & $0.70(0.29-1.69)$ \\
\hline Same week & $0.59(0.34-1.01)$ & $0.53(0.27-1.07)$ & $0.70(0.29-1.69)$ \\
\hline 1 week after & $0.77(0.47-1.24)$ & $0.87(0.50-1.50)$ & $0.56(0.21-1.50)$ \\
\hline 2 weeks after & $1.22(0.83-1.78)$ & $1.26(0.80-2.00)$ & $1.12(0.55-2.25)$ \\
\hline 3 weeks after & $0.77(0.47-1.24)$ & $0.60(0.31-1.16)$ & $1.12(0.55-2.25)$ \\
\hline 4 weeks after & $0.81(0.51-1.29)$ & $0.93(0.55-1.58)$ & $0.56(0.21-1.50)$ \\
\hline \multicolumn{4}{|c|}{ Fathers, around child's birth } \\
\hline 4 weeks before & $0.81(0.51-1.29)$ & $0.87(0.50-1.51)$ & $0.68(0.28-1.64)$ \\
\hline 3 weeks before & $0.63(0.37-1.07)$ & $0.54(0.27-1.08)$ & $0.81(0.36-1.82)$ \\
\hline 2 weeks before & $0.72(0.44-1.18)$ & $0.74(0.41-1.34)$ & $0.68(0.28-1.64)$ \\
\hline 1 week before & $0.94(0.61-1.45)$ & $1.21(0.76-1.93)$ & $0.41(0.13-1.26)$ \\
\hline Same week & $0.72(0.44-1.18)$ & $0.81(0.46-1.43)$ & $0.54(0.20-1.45)$ \\
\hline 1 week after & $1.12(0.75-1.67)$ & $1.28(0.81-2.01)$ & $0.81(0.36-1.82)$ \\
\hline 2 weeks after & $1.12(0.75-1.67)$ & $1.07(0.65-1.77)$ & $1.22(0.63-2.36)$ \\
\hline 3 weeks after & $0.67(0.40-1.12)$ & $0.67(0.36-1.25)$ & $0.68(0.28-1.64)$ \\
\hline 4 weeks after & $0.81(0.51-1.29)$ & $0.94(0.55-1.60)$ & $0.54(0.20-1.45)$ \\
\hline
\end{tabular}

The numbers refer to mortality rate ratios (with $95 \%$ confidence intervals), i.e., the ratio of the mortality rate during each study week and the mortality rate outside these weeks, standardised for effects of control variables

Week refers to the anniversary $\mp 3$ days

Control variables, whose effects are not shown here, are parent's age (13-29, 30-39, 40-49, 50-59, or 60-90 years), observation year (1973-1981, 1982-1990, 1991-1999, or 2000-2008), time since child's death (0-2, 3-6, 7-11, 12-17, 18-24, or 25-35 years ago), mother's age at delivery (13-20, 21-25, 26-30, 31-35, and 36-49 years), child's sex (boy or girl), child's birth order (1, 2, 3, or 4-17), number of siblings $(0-1,2,3$, or 4-16), multiplicity (single or multiple birth), and main cause of child's death (where applicable: cardiovascular disease, suicide, other external cause, sudden infant death syndrome, congenital malformation, or any other cause)

Inclusion of the control variables have marginal effects on the standardised estimates reported here

Dummies for deaths around Christmas and Midsummer do not provide statistical improvement to any model and are therefore not included in the results referred to here 
Table 5 Standardised mortality rate ratios of mothers and fathers at the death week and birth week of a deceased minor child, by child's age at death

\begin{tabular}{llll}
\hline & $0-17$ years & Infants & $1-17$ years \\
\hline Mothers, week of child's death & $1.46(0.98-2.17)$ & $1.29(0.78-2.12)$ & $1.89(0.97-3.67)$ \\
Mothers, week of child's birth & $1.04(0.65-1.66)$ & $0.96(0.54-1.70)$ & $1.24(0.55-2.80)$ \\
Fathers, week of child's death & $0.60(0.34-1.03)$ & $0.54(0.27-1.09)$ & $0.71(0.29-1.71)$ \\
Fathers, week of child's birth & $0.74(0.45-1.20)$ & $0.82(0.46-1.45)$ & $0.57(0.21-1.51)$ \\
\hline
\end{tabular}

The numbers refer to mortality rate ratios (with $95 \%$ confidence intervals), i.e., the ratio of the mortality rate during the study week and the mortality rate outside this week, standardised for effects of control variables

Week refers to the anniversary $\mp 3$ days

Control variables are the same as in Table 4

Accordingly, earlier studies have also found higher mortality among mothers than among fathers after the loss of a child $[1,28]$.

We found a higher mortality risk around the death week among mothers who lost a child aged 1-17 years as compared to those who lost an infant child, which might reflect stronger attachment between the mother and the child with increasing age. Parents of fertile age who lose an infant child might also be more inclined to give birth to a new child [30]. The new child's entry into the family may interrupt, distort, and delay the mourning process and thereby buffer health consequences of the child's death [35].

We also found that cardiovascular diseases and suicides were more common causes of death in mothers who died around the anniversary than in the total population of bereaved mothers. Accordingly, the temporal character of the anniversary reaction suggest that we should primarily expect consequences for acute causes of death such as myocardial infarction and suicide while it seems less likely that deaths due to chronic diseases underlies the anniversary effect, which may be more randomly distributed in the population of bereaved parents.

Finally, we found that the excess mortality around the death date of a child was associated primarily with child deaths from external causes if the child died at non-infant age, and with child deaths from sudden infant syndrome if the child died at infant age. Unexpected parental deaths due to unnatural causes such as sudden infant syndrome, injuries, suicides and other external causes, could have a stronger impact on parents as these types of deaths are more traumatic and could contribute to complicated and prolonged grief [36, 37]. Thus, anniversaries could be more stressful for parents who experienced child deaths from external causes [8]. Such deaths might also lead to higher risk of depression and psychiatric disorders in parents around the anniversary and increase the suicide risk [38, 39]. Natural deaths that are due to diseases are generally less disruptive and difficult to cope with and could also lead to less severe anniversary reactions.

Some limitations of the register based data should be noted. A necessary prerequisite for conducting research on anniversary reactions is the access to large sources of data. However, even though we studied mortality in mothers following all child deaths in Sweden between 1973 and 2008 using the total population one must bear in mind that deaths in both children and mothers at the relatively young ages studied are extremely rare events. Studying parental deaths during a limited time frame (the death week around child deaths) additionally limits the number of deaths upon which one draws inference. Because of the limited power the results should be cautiously interpreted. Moreover, detailed information on personal and relational characteristics is required to entirely exclude the possibility of residual confounding. Ideally, one would also like to have detailed information on diseases from medical records, and more information on shared social environment, health behaviours and psychological states in order to exclude the possibility of confounding. For instance, there is a possibility, although not very likely, that some unobserved variables could contribute to both child deaths and increased mortality among parents around the anniversary. For instance children in families where one or both parents have a psychiatric disease may have a higher risk of dying of accidents due to lack of parental supervision. These parents may in turn have a higher suicide mortality around anniversaries because of their poor psychological condition that both contributed to the child's death and the increased risk of suicide around the anniversary. An especially important task for future research is to test the relative importance of underlying mechanisms linking child deaths and mortality in bereaved parents around the anniversary after the death, such as higher parental depression rates, deterioration of health behaviours, and onset of acute psycho-physiological stress mechanisms which would require detailed longitudinal information on bereaved parents. 
The findings from this study and previous studies in the field [1, 10-18] suggest that broader collateral health effects on parents following the death of a child should be acknowledged, and particularly that bereavement reactions may be triggered around anniversaries several years since the loss [40]. Yet, more research is needed also on how to support parents following the loss of a child.

To our knowledge this study is the first using large national registry data to demonstrate higher mortality among mothers around the anniversary since the death of a child, indicating that bereavement has a causal effect on health. Future studies should examine whether also other parental health outcomes than mortality are affected, whether other types of familial losses contributes to similar anniversary reactions, and why father's mortality risk seems to be depressed around the anniversary.

Acknowledgments M.R. was funded by the Swedish Research Council (Grant No. 2011-1649).

Conflict of interest None.

Ethical standard The data used in this study was approved by the Regional Ethical Review board of Stockholm (No. 2014/415-31/5).

\section{References}

1. Li J, Precht DH, Mortensen PB, et al. Mortality in parents after death of a child in Denmark: a nationwide follow-up study. Lancet. 2002;361:363-7.

2. Sanders CM. A comparison of adult bereavement in the death of a spouse, child, and parent. Omega. 1979;10:303-22.

3. Middleton W, Raphael B, Burnett P, et al. A longitudinal study comparing bereavement phenomena in recently bereaved spouses, adult children and parents. Aust Psychiatry. 1998;32:235-41.

4. Sirki K, Saarinen-Pihkala UM, Hovi L. Coping of parents and siblings with the death of a child with cancer: death after terminal care compared with death during active anticancer therapy. Acta Paediatr. 2000;89:717-21.

5. McEwen BS. Protective and damaging effects of the stress mediators. N Engl J Med. 1998;338:171-9.

6. Eshtehardi P, Koestner SC, Adorjan P, et al. Transient apical ballooning syndrome-clinical characteristics, ballooning pattern, and long-term follow-up in a Swiss population. Int J Cardiol. 2009;135:370-5.

7. Cohen S, Kessler R, Gorden U. Strategies for measuring stress in studies of psychiatric and physical disorders. In: Cohen S, Kessler $\mathrm{R}$, Gorden U, editors. Measuring stress. New York: Oxford University Press; 1995. p. 3-26.

8. Hendrickson KC. Morbidity, mortality, and parental grief: a review of the literature on the relationship between the death of a child and the subsequent health of parents. Palliat Support Care. 2009; 7:109-19.

9. Rostila M, Saarela J. Time does not heal all wounds. Mortality following the death of a parent. J Marriage Fam. 2011;73:236-49.

10. Kreicbergs U, Valdimarsdottir U, Onelov E, et al. Anxiety and depression in parents 4-9 years after the loss of a child owing to malignancy: a population-based follow-up. Psychol Med. 2004;34:1431-41.
11. Li J, Johansen C, Olsen J. Cancer survival in parents who lost a child: a nationwide study in Denmark. $\mathrm{Br} \mathrm{J}$ Cancer. 2003;88:1698-701.

12. Li J, Hansen D, Mortensen PB, et al. Myocardial infarction in parents who lost a child: a nationwide cohort study in Denmark. Circulation. 2002;106:1634-9.

13. Murphy SA, Lohan J, Braun T, et al. Parents' health, health care utilization, and health behaviours following violent deaths of their 12- to 28-year-old children: a prospective longitudinal analysis. Death Stud. 1999;23:589-616.

14. Olsen J, Li J, Precht DH. Hospitalization because of diabetes and bereavement: a national cohort study of parents who lost a child. Diabet Med. 2005;22:1338-42.

15. Qin P, Mortensen PB. The impact of parental status on the risk of completed suicide. Arch Gen Psychiatry. 2003;60:797-802.

16. Birenbaum LK, Stewart BJ, Philips DS. Health status of bereaved parents. Nurs Res. 1996;45:105-9.

17. Kvikstad A, Vatten LJ. Risk and prognosis of cancer in middleaged women who have experienced the death of a child. Int $\mathbf{J}$ Cancer. 1996;67:165-9.

18. Li J, Johansen SP, Olsen J. Stroke in parents who lost a child. A nationwide follow-up study in Denmark. Neuroepidemiology. 2003;22:211-6.

19. Rubin SS. The death of a child is forever: the life course impact of child loss. New York: Cambridge University Press; 1993.

20. Hasui C, Kitamura T. Aggression and guilt during mourning by parents who lost an infant. Bull Menninger Clin. 2004;68:245-59.

21. Arnold J, Gemma PB, Cushman LF. Exploring parental grief: combining quantitative and qualitative measures. Arch Psychiatr Nurs. 2005; 19:245-55.

22. Dyregrov A, Matthiesen SB. Parental grief following the death of an infant-a follow-up over one year. Scand $\mathrm{J}$ Psychol. 1991;32:193-207.

23. Martinson IM, Davies B, McClowry S. Parental depression following the death of a child. Death Stud. 1991;15:259-67.

24. Vance JC, Najman JM, Thearle MJ, et al. Psychological changes in parents eight months after the loss of an infant from stillbirth, neonatal death, or sudden infant death syndrome - a longitudinal study. Pediatrics. 1995;95:933-8.

25. Umberson D, Chen M. Effects of a parent's death on adult children: relationship salience and reaction to loss. Am Sociol Rev. 1994;59:152-68.

26. Bowlby J. Attachment and loss, vol. 1. London: Hogarth; 1970.

27. Rossi AS, Rossi PH. Of human bonding: parent-child relations across the life course. New York: Aldine de Gruyter; 1990.

28. Rostila M, Saarela J, Kawachi I. Mortality in parents following the death of a child: a nationwide follow-up study from Sweden. J Epidemiol Community Health. 2012;66:927-33.

29. Rostila M, Saarela J, Kawachi I. The forgotten griever: a nationwide follow-up study of mortality subsequent to the death of a sibling. Am J Epidemiol. 2012;176:338-46.

30. Olmsted R, Poznanski EO. The "replacement child": a saga of unresolved parental grief. J Pediatr. 1972;81:1190-3.

31. Gabriel MA. Anniversary reactions: trauma revisited. Clin Soc Work J. 1992;20:179-92.

32. Renvoize EB, Jain J. Anniversary reactions. Br J Psychiatry. 1986;148:322-4.

33. Barker E, O'Gorman JG, De Leo D. Suicide after a loss or around anniversary times. In: De Leo D, Cimitan A, Dyregov K, Grad O, Andriessen K, editors. Bereavement after traumatic death: helping the survivors. Göttingen: Hogrefe Publishing; 2014.

34. Bunch J, Barraclough B. The influence of parental death anniversaries upon suicide dates. Br J Psychiatry. 1971;118:621-6.

35. Legg C, Sherick I. The replacement child-a developmental tragedy: some preliminary comments. Child Psychiatry Hum Dev. 1976;7:113-226. 
36. Raphael B, Martinek N. Assessing traumatic bereavement and posttraumatic stress disorder. In: Wilson JP, Keane TM, editors. Assessing psychological trauma and PTSD. New York: Guilford Press; 1997. p. 373-95.

37. Kaltman S, Bonanno GA. Trauma and bereavement: examining the impact of sudden and violent deaths. J Anxiety Disord. 2003;17:131-47.
38. Merlevede E, Spooren D, Henderick H, et al. Perceptions, needs and mourning reactions of bereaved relatives confronted with a sudden unexpected death. Resuscitation. 2004;61:341-8.

39. Parkes CM. Bereavement in adult life. BMJ. 1998;316:856-9.

40. Milberg A, Olsson E-C, Jakobsson M, et al. Family members' perceived needs for bereavement follow-up. J Pain Symptom Manage. 2008;1:58-69. 